\title{
Offshore megalopae of Callinectes sapidus: depth of collection, molt stage and response to estuarine cues
}

\author{
Donna L. Wolcott ${ }^{1}$, Mona C. De Vries ${ }^{2}$ \\ ${ }^{1}$ Department of Marine, Earth and Atmospheric Sciences, North Carolina State University, Raleigh, North Carolina \\ 27695-8208, USA \\ ${ }^{2}$ Duke University Marine Laboratory, Beaufort, North Carolina 28516, USA
}

\begin{abstract}
Megalopae of Callinectes sapidus from offshore waters can shorten the interval to metamorphosis to first crab in response to cues common to settlement habitat within estuaries. Observations were made on postlarvae (megalopae) collected offshore from the Chesapeake Bay (USA) over a period of several days in October 1992, fairly late in the recruitment season. Megalopae exposed to a combination of water from the marsh surface and low salinity accelerated metamorphosis by $10 \%$. Physiological condition of postlarvae collected both in surface waters and from the bottom was compared, using molt stage, progress to molt, and survivorship as indicators. No differences in physical condition were detected, and no megalopae were in active premolt. The pattern of progress to metamorphosis implies that both benthic and surface postlarvae are able to delay metamorphosis, and that the initiation of behaviors that move megalopae from surface waters is temporally segregated from advance to metamorphosis.
\end{abstract}

KEY WORDS: Larva $\cdot$ Callinectes $\cdot$ Recruitment $\cdot$ Metamorphosis

\section{INTRODUCTION}

The blue crab Callinectes sapidus exemplifies those organisms that utilize estuaries as adults, but whose larval development occurs offshore. Based on studies using a variety of collecting techniques, including artificial settlement habitats, and water column and bottom sampling, recruitment of blue crabs to the estuary is most likely by the megalopal, or postlarval, stage. As is true for most of these estuarine reinvaders, megalopae of C. sapidus cannot rely on swimming alone to reenter estuaries. Although they are capable of mean horizontal speeds of approximately $5 \mathrm{~cm} \mathrm{~s}^{-1}$ (Luckenback \& Orth 1992), the offshore component of the current off Chesapeake Bay (USA) mouth frequently attains speeds of $10 \mathrm{~cm} \mathrm{~s}^{-1}$ (Johnson 1985). Blue crab larvae are routinely advected tens of kilometers offshore from the Chesapeake Bay (McConaugha 1988) and the Delaware Bay (USA) (Epifanio et al. 1984). The transport trajectory of larvae in the horizontal plane is determined by the water current in which they reside. However, by moving vertically in the water column, larvae may be entrained in water masses with alternative trajectories appropriate for reinvasion of the estuary, and subsequent retention there (Hardy 1935, Johnson 1985, Boicourt 1988, Epifanio 1988).

Although megalopae of Callinectes sapidus studied in the laboratory exhibit behavior that would permit precise regulation of depth in the water column (Sulkin \& van Heukelem 1986, Naylor \& Isaac 1973, Tankersley et al. in press), the majority of megalopae in offshore waters are near the surface (McConaugha 1988). These surface waters are advected into estuaries during appropriate wind events. However, since bulk flow of surface waters from estuaries is seaward, larvae which remained at the surface would be reexported from the estuary. Not surprisingly, megalopae within estuaries are not exclusively found at the surface. They appear to be employing tidal stream transport, behaviorally regulating their depth such that 
they move up-estuary. Megalopae are generally most abundant in surface layers on nocturnal flood tides, and absent from the water column on ebbing tides (Epifanio et al. 1984, Mense \& Wenner 1989, De Vries et al. 1994, E. J. Olmi III unpubl.).

There is a clear selective advantage to moving promptly up the estuary. Areas of submerged aquatic vegetation and unvegetated shallows provide nursery areas for juveniles of many species, including fish and invertebrates (Heck \& Thoman 1984, Orth \& van Montfrans 1987, Ruiz et al. 1993). For the blue crab, both reduced predation (Wilson et al. 1990) and enhanced growth (Perkins 1993) accrue to juveniles inhabiting vegetation. Consequently, there exists a selective advantage for adaptations which enhance recruitment to habitat that improves survival and hence fitness. Based on the relative abundances of megalopae and first stage juveniles, metamorphosis to first crab appears to occur in association with vegetation, when vegetated habitat is available (Orth \& van Montfrans 1987, Lipcius et al. 1990, Olmi et al. 1990). Candidate mechanisms underlying the association include selective settlement and/or differential survival.

The behavioral shift from negative geotaxis, which maintains larvae at the surface, to the complex of behaviors employed in tidal stream transport is critical for retention in the estuary once ingress has occurred. What triggers the shift is unknown. Potential mechanisms for initiating either tidal stream transport or metamorphosis include: (1) ontogenetic change in behavior, in the absence of environmental cues (determinant development); (2) behaviorial changes in response to cues from the environment (e.g. salinity drop or odors from the estuary); and (3) a combination of the two (e.g. an initial refractory period followed by a receptive period). Megalopae at the mouth of Delaware Bay have made the shift to tidal stream transport, based on their distribution in the water column (Epifanio et al. 1984). Megalopae in the mouth of the Chesapeake are no longer exclusively high in the water column, suggesting that here too, the behavioral shift has been initiated (Maris 1986). Beyond this coarse spatial characterization, the temporal and spatial patterns of the behavioral shift are uncharacterized.

Sulkin \& Epifanio (1986) propose that megalopae move deeper in the water column as they mature and approach metamorphosis. An ontogenetic mechanism for leaving the surface would imply that benthic megalopae are older than shallow ones. A cue-driven shift to the benthos requires that benthic megalopae have responded to an environmental cue. An opportunity to investigate potential mechanisms of the behavioral shift to tidal stream transport is provided by the exis- tence of a persistent and not inconsequential percentage of megalopae which are benthic even in collections made far offshore (12 to $25 \%$, Johnson 1983 ; $12 \%$, McConaugha 1988). To test the null hypothesis that benthic larvae are physiologically no different from shallow larvae collected at the same site, we scored molt stage and monitored interval until metamorphosis and survival for megalopae collected from the surface and at depth. A priori, linkage between the behavioral shift to the benthos and a commitment to metamorphosis is not assumed.

To test for cue-driven differences in development, a second experiment was conducted to determine if megalopae in the neuston offshore respond to chemical cues from a marsh surface independently from, or in concert with, salinity cues. The response variable was interval until metamorphosis.

\section{MATERIALS AND METHODS}

Larvae of the blue crab Callinectes sapidus were collected from various depths in 2 areas, one centered at $37.00^{\circ} \mathrm{N}, 75.50^{\circ} \mathrm{W}$, and another at $37.02^{\circ} \mathrm{N}, 75.45^{\circ} \mathrm{W}$, 10 to $12 \mathrm{~km}$ and 18 to $19 \mathrm{~km}$ off the mouth of the Chesapeake Bay, respectively, over a period from 19 to 24 October 1992, from the RV 'Cape Hatteras'. A neuston net sampled the surface, closing bongo nets were used for discrete sampling of the water column, and an epibenthic sled was used for sampling larvae within $1 \mathrm{~m}$ of the bottom, which ranged from 11 to $13 \mathrm{~m}$. The megalopal size fraction was collected on a $1 \mathrm{~mm}$ screen, and blue crab megalopae sorted into 8 inch (ca $20 \mathrm{~cm}$ ) culture dishes.

Physiological status of shallow vs deep megalopae. Megalopae collected via epibenthic sled from $11 \mathrm{~m}$ (20 October) and $12 \mathrm{~m}$ (21 and 22 October), and via neuston net (19 to 22 October) were housed individually in the $3 \times 2 \times 3 \mathrm{~cm}\left(18 \mathrm{~cm}^{3}\right)$ compartments of plastic tackle boxes containing 32 ppt seawater collected on site. Tackle boxes, and water, were changed daily, with the megalopae occupying the same compartment in consecutive boxes. Boxes were washed with cake Bonami ${ }^{\otimes}$, rinsed copiously with tap water and soaked and rinsed in distilled water. Megalopae were fed once daily with plankton collected from the upper $1 \mathrm{~m}$ using a $73 \mu \mathrm{m}$ plankton net and retained on a $212 \mu \mathrm{m}$ screen, and were maintained at 17 to $18^{\circ} \mathrm{C}$, first in an incubator aboard ship, and later in a temperature-controlled room at NCSU. Each day through 25 October, each megalopa was examined at $400 \times$, using a depression slide and coverslip, to determine molt stage as judged by epidermal retraction in the rostral spine (Karen Metcalf, Virginia Institute of Marine Science, pers. comm.). After 25 October, megalopae were screened 
twice daily. Time of metamorphosis to juvenile was noted.

Metamorphosis in response to environmental cues. A subset of megalopae, all collected during a $2 \mathrm{~h}$ period from the neuston on 22 October in $17^{\circ} \mathrm{C}$ water, $18 \mathrm{~km}$ from the Chesapeake Bay mouth, was randomly divided into 1 of 4 treatments, and housed individually as above, in complete block arrays. Treatments consisted of 2 sources of water, seawater collected on site and seawater covering blocks of marsh collected at Causeway Marsh in Beaufort, NC, USA, and maintained on board ship with aeration. Salinities of $32 \mathrm{ppt}$ and 26 ppt were prepared from each water source, using distilled water to reduce salinity and Instant Ocean to increase salinity where necessary. Fifteen ml of the appropriate treatment was added to each compartment. Separate containers were used to prepare treatment waters, and separate pipettes used to transfer larvae from marsh and shelf treatments. Boxes were changed and animals fed as above. Megalopae were checked daily at 09:00 and 21:00 h for metamorphosis.

Statistics. To test for differences between treatments in the marsh water and salinity experiment, Friedman's test for 2-way classification for randomized complete block designs with more than 2 treatments was used (a non-parametric test). Data were transformed using the natural logarithm, and incomplete blocks were deleted. Pairwise comparison of means was performed using a multiple range test employing least significant differences. An ANOVA test on transformed data exploring main effects and interactions and using Type III sum of squares to account for missing values was used to detect significant block and treatment effects. A 2-sample test using the $t$-statistic compared the marsh/low salinity treatment against all other treatments, and differences in interval to metamorphosis between benthic and neustonic megalopae.

\section{RESULTS}

\section{Physiological status of shallow vs benthic megalopae}

All megalopae examined for molt stage, collected from surface waters and the bottom, were judged to be in intermolt $(n=116)$. Progress toward molt was accurately monitored by noting the degree of epidermal retraction in the rostral spine (Fig. 1), a rapid, noninvasive procedure. Over the $10 \mathrm{~d}$ period required for all megalopae to reach metamorphosis, mortality was $3.7 \%(\mathrm{n}=163)$. Mortality was comparable in megalopae collected from surface and bottom samples. Successful metamorphosis occurred in $95.6 \%$ of benthic megalopae ( $n=23$ ), and $96.4 \%$ of megalopae collected

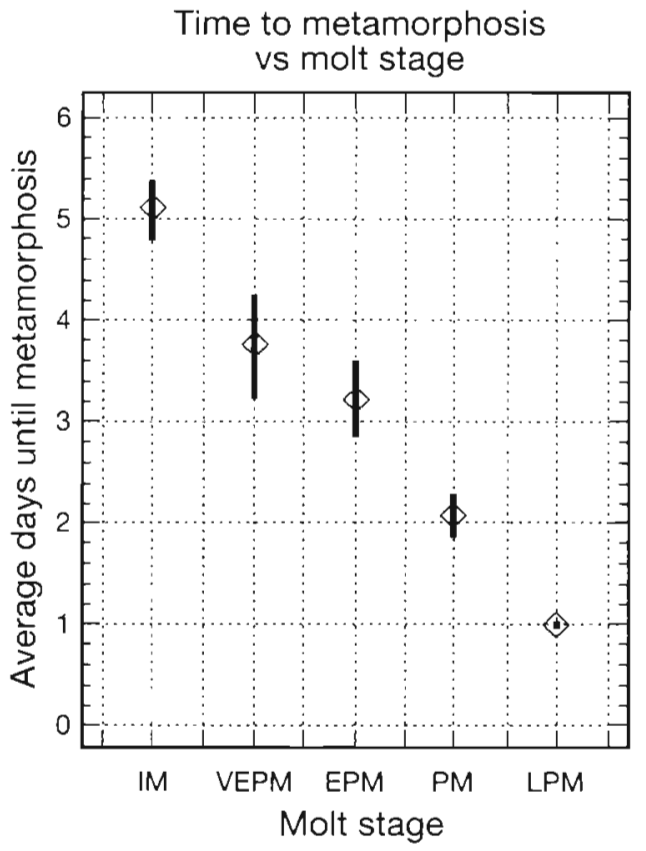

Fig. 1 Callinectes sapidus. Precision of estimating time until metamorphosis using the degree of epidermal retraction in the rostral spine of living megalopae. IM: intermolt $(n=28$, no retraction); VEPM: very early premolt $(n=4 \text {, retraction }<5 \%)_{;}$ EPM: early premolt $(n=14$, retraction $<10 \%)$; PM: premolt $(\mathrm{n}=28$, retraction 20 to $80 \%)$; LPM: late premolt $(n=6$, retraction $\geq 90 \%$ ). Error bars are $\pm 1 \mathrm{SE}$ of the mean

above $1 \mathrm{~m}(\mathrm{n}=140)$. There was no significant difference in the time it took to reach metamorphosis between shallow and deep megalopae (5.3 d; Table 1).

\section{Metamorphosis in response to environmental cues}

Cues from the marsh environment accelerated metamorphosis. In combination, reduced salinity (26 ppt) and water from the marsh surface reduced the average time to reach metamorphosis from 4.9 to $4.5 \mathrm{~d}$ post collection ( $p=0.03$, Friedman analysis; Table 1). No crab metamorphosed prior to Day. 4 Faster progress to metamorphosis in low salinity marsh water compared to full strength seawater was confirmed using pairwise comparisons of means $(p<0.05)$. Factorial analysis which partitioned differences between main effects and interactions showed each to be marginally significant $(0.05<p<0.1)$. Block was a significant source of variability $(p=0.025)$.

One unanticipated result was that all megalopae held in tackle boxes metamorphosed to first crab within $10 \mathrm{~d}$ even when no intentional environmental cues were provided. Megalopae collected during the same cruise and held in mass cultures [ 30 gal (ca 115 l) garbage cans with $5 \mathrm{~mm}$ plastic screening for substra- 
Table 1. Callinectes sapidus. Days elapsed from date of collection until metamorphosis in crabs, as affected by depth of collection, water source and salinity. Values not sharing letters are significantly different at $p=0.05$

\begin{tabular}{|lcccccc|} 
& Surface & \multicolumn{2}{c}{ Bottom } & \multicolumn{2}{c}{ Seawater } & \multicolumn{2}{c}{ Marsh } \\
& $<1$ m depth & $11-13$ m depth & $32 \mathrm{ppt}$ & $26 \mathrm{ppt}$ & $32 \mathrm{ppt}$ & $26 \mathrm{ppt}$ \\
\hline Average & 5.283 & 5.262 & $4.932^{\text {at }}$ & $4.886^{\mathrm{bc}}$ & $4.909^{\mathrm{bc}}$ & $4.475^{\mathrm{c}}$ \\
Standard error & 0.219 & 0.317 & 0.231 & 0.147 & 0.160 & 0.138 \\
Sample size & 30 & 21 & 22 & 22 & 22 & 22 \\
\hline
\end{tabular}

tum and with aeration] for transport to various labs, did not appear to advance to molt as rapidly, although no quantitative data are available.

Time to reach metamorphosis differed slightly between the shallow vs deep experiment and the control group in the environmental cues test (5.3 vs 4.9 d). Daily handling for molt stage analysis in the shallow vs deep group may have delayed metamorphosis slightly. A more likely explanation is that of sample variance. All megalopae used in the environmental cue experiment were collected in a $2 \mathrm{~h}$ interval from the neuston, to control variance. Conversely, the megalopae used in the benthos vs surface test were collected over a $4 \mathrm{~d}$ period at 2 distances offshore. ANOVA revealed no statistical linkage between stratum vs date of collection in time to metamorphosis.

\section{DISCUSSION}

Megalopae offshore appear to be in intermolt. None of the megalopae examined showed evidence of being in active premolt, regardless of depth of collection or distance offshore, and yet all metamorphosed to first crab fairly synchronously with a median of $5 \mathrm{~d}$ after collection. Megalopae collected on sequential days did not take progressively less time to reach metamorphosis, as would be the case if sampling from a population already committed to metamorphose. This implies that megalopae were stimulated to initiate progress toward metamorphosis soon after collection, since it takes approximately $4 \mathrm{~d}$ to reach metamorphosis under these conditions, from the earliest stages of premolt detectable by the rostral spine method (Fig. 1).

A similar pattern of progress to metamorphosis was reported by McConaugha (1988) for megalopae collected in $28 \mathrm{ppt}$, and reared in the lab in a variety of lower salinities. As he states, the 4 to $5 \mathrm{~d}$ delay between initiation of experimental treatments and ecdysis is consistent with time required to reinitiate a molt cycle that has been suspended in early premolt (McConaugha 1988), although molt staging was not done in that study. It may also represent the time required to reach metamorphosis from intermolt, once appropriate cues are encountered, i.e. classic release from delayed metamorphosis (Chia \& Rice 1978, Burke 1984). Comparable time to metamorphosis in separate studies (ours and McConaugha 1988), and in megalopae collected over a $4 \mathrm{~d}$ period and $8 \mathrm{~km}$ of ocean within a single study, strongly implicates extrinsic rather than intrinsic factors in initiation of metamorphosis under laboratory conditions.

This study demonstrates that cues common in settlement areas reduce the amount of time required for blue crab megalopae to reach the juvenile stage by $10 \%$, once the cues are encountered. The ability to manipulate the timing of metamorphosis using appropriate cues from the habitat has obvious gains in fitness for blue crabs, given the stochastic nature of transport of blue crab larvae into the estuary, and the patchiness of preferred nursery areas. Enhanced metamorphosis in response to cues from the environment is common in the marine environment (Chia \& Rice 1978, Burke 1984, Morse 1990). Cues from the substrate play an important role in inducing metamorphosis in species that are obligated to remain in a particular site once site selection is complete (barnacles, Crisp 1979; reef building worms, Jensen \& Morse 1984, Pawlik 1988). Such cues are also important to larvae of species that are still mobile after settlement, but that must recruit to specific habitats for successful completion of the juvenile stage (molluscs, Morse 1985) or whose habitat is patchy (reef fishes, Kingsford \& Milicich 1987; fiddler crabs, Christy 1989, O'Connor 1991).

Using multiple cues to modulate metamorphosis increases the likelihood that megalopae will metamorphose in appropriate habitat and has also been reported for other soft-sediment dwelling animals (Suer \& Phillips 1983, Rice 1986). The fiddler crab Uca pugilator can both delay metamorphosis in the absence of cues, and accelerate metamorphosis in their presence. The interval required to reach metamorphosis from the molt to megalopa is reduced 2- to 3-fold in the presence of sediment from adult habitat. In the presence of sediment, metamorphosis occured as early as $2 \mathrm{~d}$ after the molt to the megalopal stage, and all had metamorphosed within $8 \mathrm{~d}$ (mean $4.7 \mathrm{~d}$ ). In the absence of sediment, some megalopae had still not metamorphosed after $30 \mathrm{~d}$, and mean time to metamorphosis was $12.9 \mathrm{~d}$ (Christy 1989). O'Connor (1991) showed that 2 cues, 
adult crabs and sediment, must both be present for initiation of metamorphosis in $6 \mathrm{~d}$ old megalopae, and that megalopae reared continuously in the presence of both cues metamorphosed sooner than in the presence of only 1 cue, or no cue.

There is circumstantial evidence for multiple cues for behavioral and physiological changes associated with recruitment in the blue crab. Distribution of postlarvae within the Chesapeake Bay is consistent with tidal stream transport, which reflects vastly different behaviors than the shallow distribution offshore. Yet nearly half of the postlarvae well inside the estuary $(24 \mathrm{~km})$ have not initiated premolt (Metcalf \& Lipcius 1992). This implies spatial and temporal differences in factors responsible for presettlement behaviors and metamorphosis.

We must emphasize that estuarine cues were not shown to induce metamorphosis in the current study. All megalopae in all treatments metamorphosed within $10 \mathrm{~d}$. Although exposure to low salinity and marsh habitat cues shortened the interval until metamorphosis, some other factor(s) is sufficient to start the metamorphic clock. This implies that something about the collection process or holding method stimulates megalopae to initiate progress toward metamorphosis. The factor or factors responsible for initiating premolt once collected from the plankton are unknown. Only changes in salinity, and food type, can be discounted with any degree of certainty. Temperature spikes (e.g. during sorting), altered light regime, changes in food abundance, the presence of physical structure, alteration of larval densities, unnatural turbulence regime or changes in turbidity, for example, might contribute to trigger the onset of metamorphosis. What the cue(s) in nature might be is of great interest and of critical importance in understanding recruitment in the blue crab, but may prove extremely difficult to establish, unless laboratory holding conditions can be found which do not precipitate metamorphosis.

The apparent ease with which megalopae can be triggered to metamorphose should be considered when working with megalopae in the laboratory. Costlow \& Bookhout (1959) report megalopal stage duration of 6 to $12 \mathrm{~d}$ under laboratory conditions, with increasing duration at elevated salinities (Costlow 1967). It is possible that the ability to delay metamorphosis is masked by conditions of laboratory rearing, and that once sufficient reserves are accumulated ('point of reserve saturation', Anger 1991), megalopae proceed to metamorphosis. The duration of megalopal stage as determined in the laboratory may bear little relation to the reality in the field. Tracking of particular cohorts of larvae in the field, using programmable lagrangian drifters, should permit sequential sampling and aging of megalopae.
Blue crab megalopae offshore are poised to utilize at least 2 possible methods of ingress. Megalopae throughout the water column will be advected into Chesapeake Bay during favorable wind-driven events (Johnson et al. 1984, Goodrich et al. 1989), while those near the bottom can also ride in on persistent on-shore currents (Sulkin \& Epifanio 1986). Comparable developmental states and rates of metamorphosis and survival support the null hypothesis that benthic megalopae and shallow megalopae are physiologically indistinguishable. Benthic megalopae are not moribund, and metamorphose successfully to juveniles. Using the criterion of molt stage (Lipcius et al. 1990), benthic postlarvae are not committed to metamorphose, and are not more developmentally advanced than shallow conspecifics. Consequently, given favorable advective regimes, both benthic and surface postlarvae could contribute to estuarine recruitment.

Populations of blue crabs fluctuate on an annual basis. Much of the variability stems from factors operating during recruitment and early post-settlement stages (Orth \& van Montfrans 1987, Johnson \& Hester 1989). On the supply side, pulses of larvae appear in estuaries (van Montfrans et al. 1990). Pulses frequently correlate with those meteorological events which result in onshore transport of water (Goodrich et al. 1989, Little \& Epifanio 1991). Not all favorable wind events result in major recruitment, implicating absence of larvae of the appropriate stage in the advecting water mass. The mechanism(s) driving adoption of benthic behavior has implications for the potential recruitment of megalopae found far offshore, and the relative contribution of shallow and deep megalopae under different advective regimes. Understanding the causes of variation in larval recruitment will require coordinating knowledge of the interplay between atmospheric events and water transport, and behavioral and physiological correlates in the organism.

Acknowledgements. Supported by National Science Foundation grant OCE 9002168. Thanks to Eileen Perkins, James Welch, and the crew of the RV 'Cape Hatteras' for help in collecting and sorting larvae. Karen Metcalf (Virginia Institite of Marine Science) provided training in molt staging. Tim Donato provided satellite imagery and measurements of physical oceanographic factors. Dr John McConaugha supplied tidal data. Larry Settle (NOAANMFS, Beaufort, NC) generously loaned several nets to us, as did Dr Chuck Epifanio, Univ. of Delaware.

\section{LITERATURE CITED}

Anger, K. (1991). Developmental changes in the bioenergetics of decapod larvae. Mem. Qld Mus. 31: 289-308

Boicourt, W. C. (1988). Recruitment dependence on planktonic transport in coastal waters. In: Rothschild, B. J. (ed.) 
Toward a theory on biological-physical interactions in the world ocean. Kluwer Academic Publishers, Boston, p. $183-202$

Burke, R. D. (1984). The induction of metamorphosis of marine invertebrate larvae: stimulus and response. Can. $J$. Zool. 61: 1701-1719

Chia, F.-S. (1978). Perspectives: settlement and metamorphosis of marine invertebrate larvae. In: Chia, F.-S., Rice, M. E. (eds.) Settlement and metamorphosis of marine invertebrate larvae. Elsevier North Holland, New York, p. 283-285

Chia, F.-S., Rice, M. E. (eds.) (1978). Settlement and metamorphosis of marine invertebrate larvae. Elsevier North Holland, New York

Christy, J. H. (1989). Rapid development of megalopae of fiddler crab Uca pugilator reared over sediment: implications for models of larval recruitment. Mar. Ecol. Prog. Ser. 57 : $259-265$

Costlow, J. D. Jr (1967). The effect of salinity and temperature on survival and metamorphosis of megalops of the blue crab, Callinectes sapidus. Helgoländer wiss. Meeresunters. 15: 84-97

Costlow, J. D. Jr, Bookhout, C. G. (1959). The larval development of Callinectes sapidus Rathbun reared in the laboratory. Biol. Bull. 116: 373-396

Crisp, D. J. (1979). Dispersal and re-aggregation in sessile marine invertebrates, particularly barnacles. In: Larwood, G., Rosen, R. C. (eds.) Biology and systematics of colonial organisms. Academic Press, New York, p. 319-327

De Vries, M. C., Tankersley, R. A., Forward, R. B. Jr, KirbySmith, W. W., Luettich, R. A. Jr (1994). The abundance of estuarine crab larvae is associated with tidal hydrologic variables. Mar. Biol. 118: 403-413

Epifanio, C. E. (1988). Transport of invertebrate larvae between estuaries and the continental shelf. Am. Fish. Symp. 3: $104-114$

Epifanio, C. E., Valenti, C. C., Pembroke, A. E. (1984). Dispersal and recruitment of blue crab larvae in the Delaware Bay, USA. Estuar. coast. Shelf Sci. 18: 1-12

Goodrich, D. M., van Montfrans, J., Orth, R. J (1989). Blue crab megalopal influx to Chesapeake Bay: evidence for a wind-driven mechanism. Estuar. coast. Shelf Sci. 29: $247-260$

Hardy, A. C. (1935). The plankton community, the whale fisheries and the hypothesis of animal exclusion. 'Discovery' Rep. 11: 273-360

Heck, K. L. Jr, Thoman, T. A. (1984). The nursery role of seagrass meadows in the upper and lower reaches of the Chesapeake Bay. Estuaries 7: 70-92

Jensen, R. A., Morse, D. E. (1984). Intraspecific facilitation of larval recruitment: gregarious settlement of the polychaete Phragmatopoma californica (Fewkes). J. exp. mar. Biol. Ecol. 83: $107-126$

Johnson, D. F. (1983). A comparison of recruitment strategies among brachyuran crustacean megalopae of the York River, Lower Chesapeake Bay, and adjacent shelf waters. Ph.D. dissertation, Old Dominion University, Norfolk, VA

Johnson, D. R. (1985). Wind-forced dispersion of blue crab larvae in the Middle Atlantic Bight. Cont. Shelf Res. 4: $733-745$

Johnson, D. R., Hester, B. S. (1989). Larval transport and its association with recruitment of blue crabs to Chesapeake Bay. Estuar. coast. Shelf Sci. 28: 459-472

Johnson, D. R., Hester, B. S., McConaugha, J. R. (1984). Studies of a wind mechanism influencing the recruitment of blue crabs in the Middle Atlantic Bight. Cont. Shelf Res. 3: $425-437$
Kingsford, M. J., Milicich, M. J. (1987). Presettlement phase of Parika scaber (Pisces: Monacanthidae): a temperate reef fish. Mar. Ecol. Prog. Ser. 36: 65-79

Lipcius, R. N., Olmi, E. J. III, van Montfrans, J. (1990). Planktonic availability, molt stage and settlement of blue crab postlarvae. Mar. Ecol. Prog. Ser. 58: 235-242

Little, K. T., Epifanio, C. E. (1991). Mechanism for the re-invasion of an estuary by two species of brachyuran megalopae. Mar. Ecol. Prog. Ser. 68: 235-242

Luckenbach, M. W., Orth, R. J. (1992). Swimming velocities and behavior of blue crab (Callinectes sapidus Rathbun) megalopae in still and flowing water. Estuaries 15: 186-192

Maris, R. C. (1986). Patterns of diurnal vertical distribution and dispersal - recruitment mechanisms of decapod crustacean larvae and postlarvae in the Chesapeake Bay, Virginia and adjacent offshore waters. Ph.D. thesis, Old Dominion University, Norfolk, VA

McConaugha, J. R. (1988). Export and reinvasion of larvae as regulators of estuarine decapod populations. Am. Fish. Symp. 3: 90-103

Mense, D. J., Wenner, E. L. (1989). Distribution and abundance of early life history stages of the blue crab Callinectes sapidus in tidal marsh creeks near Charleston, South Carolina. Estuaries 12: 157-168

Metcalf, K. S., Lipcius, R. N. (1992). Relationship of habitat and spatial scale with physiological state and settlement of blue crab postlarvae in Chesapeake Bay. Mar. Ecol. Prog. Ser. 82: 143-150

Morse, D. E. (1985). Neurotransmitter-mimetic inducers of larval settlement and metamorphosis. Bull. mar. Sci. 37 : $697-706$

Morse, D. E. (1990). Recent progress in larval settlement and metamorphosis: closing the gaps between molecular biology and ecology. Bull. mar. Sci. 46: 465-483

Naylor, E., Isaac, M. J. (1973). Behavioral significance in pressure responses of megalopa larvae of Callinectes sapidus and Macropipus sp. Mar. Behav. Physiol. 1: 341-350

O'Connor, N. J. (1991). Flexibility in timing of the metamorphic molt by fiddler crab megalopae Uca pugilator. Mar. Ecol. Prog. Ser. 68: 234-247

Olmi, E. J. III, van Montfrans, J., Lipcius, R, N., Orth, R. J., Sadler, P. W. (1990). Variation in planktonic availability and settlement of blue crab megalopae in the York River, Virginia. Bull. mar. Sci. 46: 230-243

Orth, R. J., van Montfrans, J. (1987). Utilization of a seagrass meadow and tidal marsh creek by blue crabs Callinectes sapidus. I. Seasonal and annual variations in abundance with emphasis on post-settlement juveniles. Mar. Ecol. Prog. Ser. 41: 283-294

Pawlik, J. R. (1988). Larval settlement and metamorphosis of two gregarious sabellariid polychaetes: Sabellaria alveolata compared with Phragmatopoma californica. J. mar. biol. Ass. U.K. 68: 101-124

Perkins, E. A. (1993). Trophic advantage to juvenile blue crabs (Callinectes sapidus) inhabiting seagrass bed habitats. M.Sc. thesis, North Carolina State University, Raleigh

Rice, M. E. (1986). Factors influencing larval metamorphosis in Golfingia misakiana (Sipuncula). Bull. mar. Sci. 39: 362-375

Ruiz, G. M., Hines, A. H., Posey, M. H. (1993). Shallow water as a refuge habitat for fish and crustaceans in non-vegetated estuaries: an example from Chesapeake Bay. Mar. Ecol. Prog. Ser. 99: 1-16

Suer, A. L, Phillips, D. W. (1983). Rapid, gregarious settlement of the larvae of the marine echiuran Urechis caupo Fisher and MacGinitie 1928. J. exp. mar. Biol. Ecol. 67: 243-259 
Sulkin, S. D., Epifanio, C. E. (1986). A conceptual model for recruitment of the blue crab, Callinectes sapidus Rathbun, to estuaries of the Middle Atlantic Bight. Can. Spec. Publ. Fish. Aquat. Sci. 92: 117-123

Sulkin, S. D., van Heukelem, W. (1982). Larval recruitment in the crab, Callinectes sapidus Rathbun: an amendment to the concept of larval retention in estuaries. In: Kennedy, $V$. (ed.) Estuarine comparisons. Academic Press, New York, p. $459-475$

Tankersley, R. A., McKelvey, L. M., Forward, R. B. Jr (in press). Responses of estuarine crab megalopae to salinity,

This article was presented by R. B. Forward J, Beaufort, N. Carolina, USA pressure and light: implications for flood tide transport. Mar. Biol.

van Montfrans, J., Perry, C. A., Orth, R. J. (1990). Daily, monthly and annual settlement patterns by Callinectes sapidus and Neopanope sayi megalopae on artificial collectors deployed in the York River, Virginia: 1985-1988. Bull. mar. Sci. 46: 214-229

Wilson, K. Able, K., Heck, K. Jr (1990). Predation rates on juvenile blue crabs in estuarine nursery habitats: evidence for the importance of macroalgae (Ulva lactuca). Mar. Ecol. Prog. Ser. 58: 243-251

Manuscript first received: November 23, 1993 Revised version accepted: March 29, 1994 